УДК 658.71

\title{
Е. Е. Дадажанова
}

Сибирский институт управления - филиал РАНХиГС, Новосибирск, e-mail:kdadazhanova@gmail.com

\section{ОСОБЕННОСТИ ГОСУДАРСТВЕННЫХ ЗАКУПОК В ЛЕЧЕБНЫХ УЧРЕЖДЕНИЯХ МО РФ}

Ключевые слова: государственные закупки, закупки для нужд обороны страны и безопасности государства, контрактная система, особенности закупок работ, товаров, услуг.

В статье раскрываются специфика и особенности государственных закупок для обеспечения нужд безопасности государства и обороны страны. Автором представлена организация закупочной деятельности военно-медицинского учреждения, функции контрактной службы, а также определены основные проблемы в сфере госзаказа для обеспечения нужд подведомственных учреждений Министерства обороны России, указаны их причины. Проблемы, определенные в ходе исследования, были разделены на две группы, общие и частные, связанные со спецификой деятельности военномедицинской организации. Практическая значимость данного исследования состоит в выявлении проблемных вопросов, исходя из которых, могут быть разработаны конкретные рекомендации по совершенствованию системы государственных закупок для обеспечения нужд лечебного учреждения Минобороны России.

\section{E. E. Dadazhanova}

Siberian Institute of Management - branch of RANEPA, Novosibirsk, e-mail:kdadazhanova@gmail.com

\section{FEATURES OF PUBLIC PROCUREMENT \\ IN MEDICAL INSTITUTIONS OF THE MINISTRY OF DEFENSE OF THE RUSSIAN FEDERATION}

Keywords: public procurements, procurement for the needs of the defense and security of the state, contract system, specifics of procurement of goods, works and services.

The article reveals the specifics and features of public procurement to ensure the needs of state security and defense of the country. The author presents the organization of the procurement activities of a military medical institution, the functions of the contract service, and also identifies the main problems in the field of public procurement to meet the needs of the institutions of the Ministry of Defense of the Russian Federation, and indicates their reasons. As a result, the problems identified in the course of the study were divided into two groups, general and specific, related to the specifics of the activities of a military medical organization. The practical significance of this research consists in identifying problematic issues, based on which specific recommendations can be developed for improving the public procurement system to meet the needs of a medical institution of the Ministry of Defense.

\section{Введение}

Актуальность данного исследования определена сложностью существующей системы государственных закупок, которая является неотъемлемой составной частью сформированной системы управления государственными финансами в экономической деятельности государственных организаций. Несмотря на то, что существующая законодательная база достаточно обширна и охватывает многие разделы госзаказа, сложности системы регулирования процесса государственных закупок присутствуют в работе каждого учреждения. Функционирование сложившейся системы прокьюремента в ведомственных учреждениях и ор- ганизациях Министерства обороны Российской Федерации имеет ряд своих индивидуальных особенностей.

Цель исследования - выявить наиболее проблемные вопросы, которые помогут разработать конкретные и практически применимые рекомендации по усовершенствованию отдельных механизмов системы государственных закупок, осуществляемых для обеспечения нужд лечебных учреждений и организаций Министерства обороны Российской Федерации.

Объектом исследования является система государственных и муниципальных закупок работ, товаров, услуг для обеспечения госнужд в лечебных организациях МО РФ. 
Предмет исследования - особенности организации и функционирования контрактной системы в сфере закупок работ, товаров, услуг для удовлетворения нужд лечебного учреждения МО РФ.

\section{Материалы и методы исследования}

Для проведения исследования использовались данные из открытых источников, размещенные на сайте Единой информационной системы и электронной торговой площадки. Применялись общенаучные методы: метод наблюдения - на примере организации работы контрактно - договорного отделения лечебного учреждения МО РФ; метод научного синтеза и обобщения, метод научного анализа.

\section{Результаты исследования и их обсуждение}

На сегодняшний день государство - это не только основной институт управления, но и активный субъект рыночных правоотношений. Экономический интерес и финансовая составляющая государства, как в частном секторе, так и в государственных вопросах, определяют главные направления развития экономики. Именно поэтому государственные закупки играют значительную роль в экономическом развитии России, а контрактная система является главным инструментом регулирования удовлетворения потребностей государства.

Контрактная система в сфере госзаказа - совокупность участников закупок и осуществляемых ими, в соответствии с законодательством Российской Федерации и нормативно-правовыми актами о контрактной системе в сфере закупок действий, которые направлены на обеспечение государственных и муниципальных нужд[1]. Согласно Федеральному закону № 44-Ф3, к участникам государственных закупок относятся:

- федеральный орган исполнительной власти по регулированию контрактной системы в сфере закупок и органы исполнительной власти субъектов Российской Федерации по регулированию контрактной системы в сфере закупок [1];

- заказчики - экономические субъекты, которые приобретают продукцию или услуги, для обеспечения госнужд.

- поставщики (подрядчики, исполнители) - юридические лица любой организационно-правовой формы, индивидуальные предприниматели, а также физические лица.
- операторы электронных площадок, обеспечивающие осуществление электронных процедур в соответствии с законодательством РФ о контрактной системе в сфере закупок

- иные участники - банки, экспертные организации и эксперты, привлекаемые заказчиками для осуществления закупок.

Постановлением Правительства РФ от 27.11.2017 г. № 1428 «Об особенностях осуществления закупки для нужд обороны страны и безопасности государства», заказчиков согласно перечню Постановления обязали проводить закупки работ, товаров, услуг закрытыми способами с использованием функционала специализированной электронной торговой площадки АCТ ГОЗ [2].

Для обеспечения нужд лечебного учреждения МО РФ создана контрактная служба, которая в своей деятельности руководствуется Конституцией Российской Федерации, федеральными законами, гражданским законодательством Российской Федерации, бюджетным законодательством Российской Федерации, нормативными правовыми актами о контрактной системе в сфере закупок товаров, работ, услуг для обеспечения государственных и муниципальных нужд, а так же внутренними положениями и приказами организации. Для эффективной работы контрактная служба взаимодействует с другими подразделениями военно-медицинской организации.

Контрактная служба лечебной организации выполняет следующие функции:

1) Создание плана-графика закупок в соответствии с потребностью военно-медицинского учреждения, подготовка изменений для внесения в план-график закупок;

2) Подготовка и публикация в ЕИС извещений о проведении закупок;

3) Разработка и подготовка документации о торгах, а также проектов контрактов;

4) Проведение закупок, заключение контрактов;

5) Участие в рассмотрении дел об обжаловании результатов определения поставщиков (подрядчиков, исполнителей), а также претензионная работа в случае ненадлежащего исполнения контракта;

6) При необходимости решения специализированных вопросов, контрактная служба может организовать дополнительные консультации с исполнителями (подрядчиками, поставщиками). Во время проведения дан- 
ных консультаций освещаются узкие вопросы с целью определения состояния конкурентной среды на соответствующих рынках, определения лучших технологий и других решений для обеспечения госнужд;

7) Осуществление иных полномочий, предусмотренных Законом 44-ФЗ.

После расчета потребности в товарах (услугах, работах), в соответствии с законом о контрактной системе, контрактный управляющий учреждения планирует закупочную деятельность. Он составляет план-график закупок, направляет его в территориальный орган Федерального Казначейства, на бумажном носителе для контроля.

Важным этапом осуществления закупок является составление технического задания. Описание объекта закупки готовят специалисты контрактного отделения совместно с уполномоченными представителями структурной службы военно-медицинского учреждения. Правильно составленное технического задания должно удовлетворять потребности Заказчика, при этом, не ограничивая количество потенциальных участников закупки. В зависимости от рода товаров, работ и услуг устанавливаются условия допуска, ограничения или преимущества для осуществления целей госзакупок.

Для обеспечения государственных нужд применяются следующие способы определения поставщика: закрытый аукцион (закрытый аукцион в электронной форме) с использованием функционала СЭТП «АСТ ГОЗ», закупки у единственного поставщика (подрядчика, исполнителя) в соответствии с п. 1, 2, 4, 6, 9, 28 ч.1 ст. 93 Закона №44-Ф3.

При осуществлении закупочной деятельности подведомственные учреждения МО РФ не размещают в единой информационной системе информацию и документы, размещение которых предусмотрено Законом №44-Ф3, за исключением извещения об осуществлении закупки, проводимой в порядке, установленном для случая, предусмотренного п. 2 ч. 2 ст. 84 Закона №44-Ф3. Участники закупки могут ознакомиться с документацией только после регистрации на специализированной электронной площадке «АСТ ГОЗ». В единой информационной системе не публикуется информация о заявках на участие в таких закупках, протоколы рассмотрения заявок и протокол определения поставщика, подписанный всеми членами комиссии.
После определения поставщика (исполнителя, подрядчика) начинается этап подписания контракта. Документы предусматривают обеспечение исполнения контракта посредством внесения денежных средств на счет или предоставлением банковской гарантии. Сведения о банковских гарантиях, предоставленных в качестве обеспечения заявок и (или) исполнения контрактов, подлежат включению органами Федерального казначейства в закрытый реестр банковских гарантий.

Заказчик не размещает информацию о заключенном контракте в Единой информационной системе. Сведения о нем должны быть включены в реестр контрактов, содержащих сведения, составляющие гостайну.

Исполнение контракта включает в себя следующие этапы:

1) Оформление заявки в письменном виде на поставку требуемого товара (оказание услуги и выполнение работы), в соответствии с условиями контракта. Заявку делает инициатор закупки - отдел снабжения.

2) Контроль сроков поставки товара (работ, услуг) по письменной заявке;

3) Получение товара, согласно условиям контракта и правилам приемки товара по количеству и качеству или подписание акта об оказании услуг, выполненных работ;

4) Составление экспертного заключения о соответствии товара условиям контракта;

5) Оплата за поставку, оказание услуги, выполнение работы по мере поступления приемочных документов в контрактную службу учреждения.

В ходе исполнения контрактов, специалисты контрактной службы направляют информацию об исполнении каждого этапа контракта в территориальный орган Федерального Казначейства, в целях ведения реестра контрактов, заключенных заказчиками. Все сведения о заключенных контрактах не подлежат публикации в ЕИС, и направляются в органы Федерального Казначейства на бумажном носителе.

Схематично организация закупочной деятельности в учреждении приведена на рисунке 1.

Проблемы, вызванные особенностями организации закупочной деятельности для обеспечения нужд подведомственных учреждений Минобороны России, можно разделить на следующие блоки. 


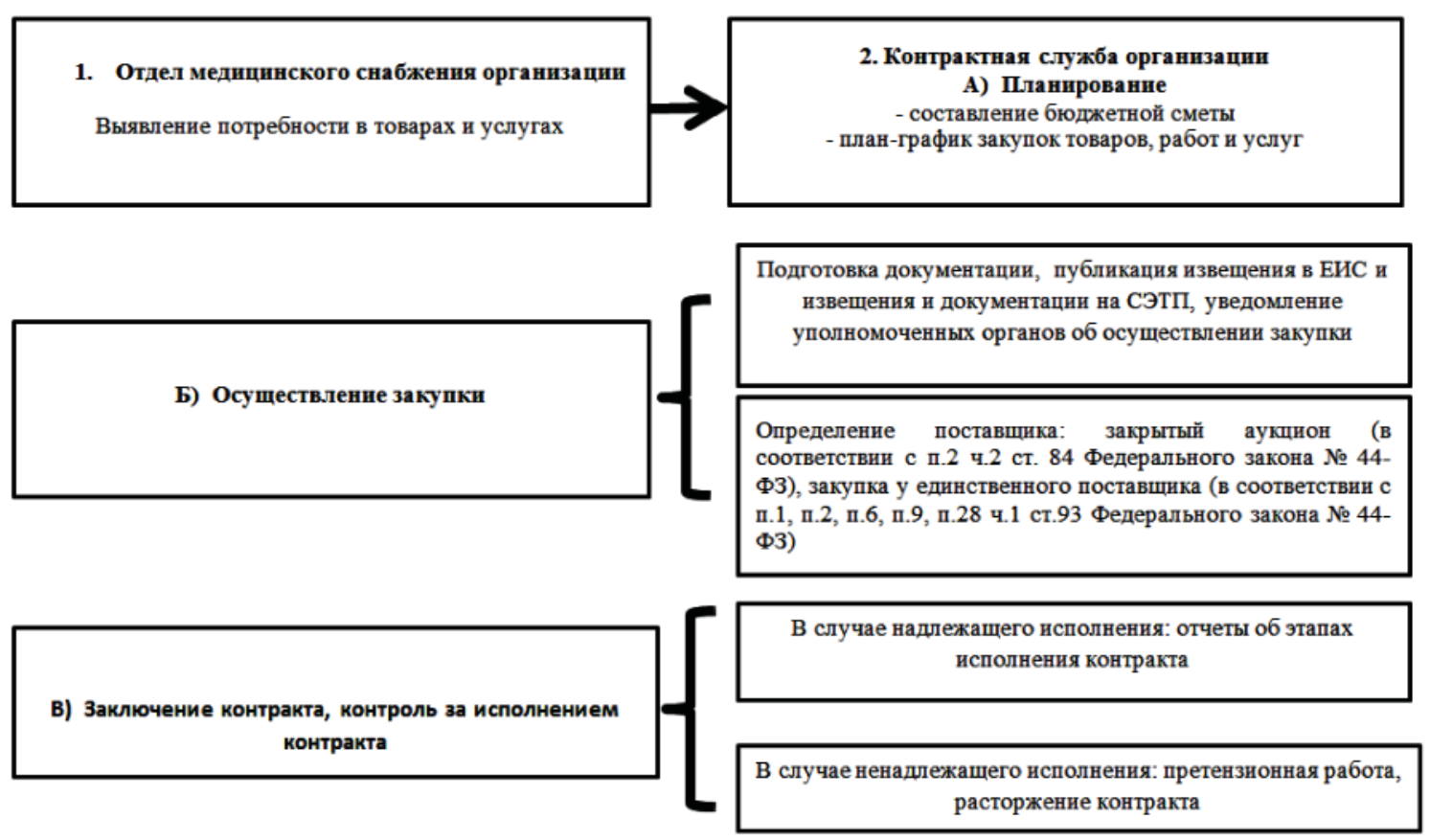

Г) Оденка эффективности работы контрактной службы, составление отчетности, документооборот с уполномоченными органами на всех этапах деятельности контрактной службы

Рис. 1. Организация закупочной деятельности в лечебном учреждении МО РФ

\begin{tabular}{|c|}
\hline Матернально-технические проблемы \\
\hline - некорректная работа ЕИС \\
-отсутствие интеграции ЕИС со специализированной \\
лектронной площадкой АСТ ГОЗ \\
- большой объем документов для печати на бумажном \\
носителе \\
- отсутствие возможности работать в ЕИС на всех этапах \\
закупки ТРу \\
\end{tabular}

Рис. 2. Материально-технические проблемы осуществления закупочной деятельности в лечебном учреждении МО РФ

1. Материально-технические проблемы (рис. 2).

Поскольку преимущественное число финансовых процедур проходит исключительно через электронные системы, а специализированный документооборот все чаще формируется в электронном виде, фактические подписи и печати заменяются электронными цифровыми подписями (квалифицирован- ными электронными подписями). Эти процессы требуют дополнительного технического обеспечение. Процедуры закупочной деятельности в военно-медицинских учреждениях МО РФ в неполной мере осуществляется за счет автоматизированных систем управления закупками, рассмотренных ранее, и отражается в ЕИС. Такая зависимость приводит к тому, что любой сбой в работе 
автоматизированных систем является значительным препятствием, а порой и невозможностью проведения закупочного процесса. Кроме того, часть документооборота происходит на бумажном носителе, что значительно затягивает процесс осуществления закупки и несет дополнительную нагрузку на специалистов контрактной службы.

2. Следующий блок проблем - проблемы нормативно-правового регулирования (рис. 3) это проблемы связанные с деятельностью учреждения в соответствии с Федеральным законом №-44 Ф3 и проблемы, связанные со спецификой работы ведомства. К первым относятся, например, отсутствие окончательного понятийного аппарата, который не раскрывает суть таких важных понятий в сфере закупок, как «эффективность закупочной деятельности», «критерии эффективности закупочной деятельности», «конкуренция в государственных и муниципальных закупках». «Законодательная размытость» требований к расчету НМЦК, в некоторых случаях, понуждают Заказчиков подбирать информацию о ценах таким образом, чтобы разброс цен был незначительным. В тех случаях, когда рынок предлагает дешевую или, наоборот, дорогую продукцию (работу, услугу) и разброс цен слишком велик, Заказчик «подводит» подходящие, для себя, коммерческие предложения [3]. К проблемным вопросам нормативно-правового регулирования, связанным с особенностями деятельности лечебного учреждения МО РФ можно отнести и противоречия в законодательной базе закупочной деятельности. В качестве наглядного примера, можно привести закупки лекарственных препаратов при наличии медицинских показаний .В качестве правовой основы в закупочной деятельности используется п. 28 ч. 1 ст. 93 Закона №44-Ф3. Здесь возникает противоречие между зако- ном и Постановлением Правительства РФ от 27 ноября 2017 года №1428, которым, как указывалось выше, такого рода заказчики обязаны проводить конкурентные процедуры только закрытыми способами. Таким образом, заказчик оказывается в затруднительном положении при осуществлении такого вида закупок. Необходимо отметить так же проведение закупок у единственного поставщика в соответствии с п. 4 ч. 1 ст. 93 Федерального закона № 44-Ф3. Так как невозможно провести закупки малого объема с использованием функционала специализированной торговой площадки, есть вероятность заключения контракта по невыгодной (завышенной) цене и несоблюдение принципа прозрачности процедуры. Все это приводит к возникновению предпосылок к коррупционной составляющей в закупочной деятельности.

Особенности нормативно-правового регулирования деятельности леченого учреждения МО РФ оказывают влияние и на уровень конкуренции. Проблема конкуренции в закупках работ, товаров и услуг учреждениями, входящими в перечень Постановления Правительства РФ № 1428 от 27.11.2017 г., обусловлена дополнительными требованиями к потенциальным участникам закупок. К таким требованиям, например, можно отнести наличие дополнительного отдельного автоматизированного рабочего места, где есть возможность использовать защищенные каналы связи, и дополнительные расходы, связанные с аккредитацией на специализированной торговой площадке «АСТ ГОЗ». Снижение конкуренции, то есть ограничение числа участников, и увеличение количества несостоявшихся торгов по причине подачи одной заявки приводят к снижению экономической эффективности закупок и перерасходу бюджетных средств [5].

Проблемы нормативно-правового обеспечения

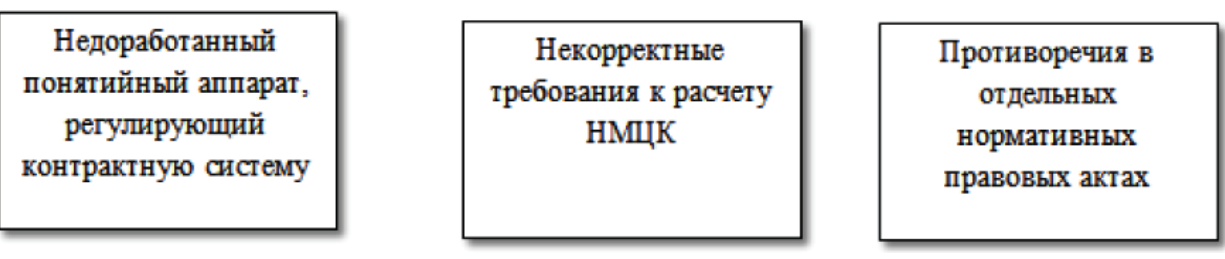

Рис. 3. Проблемы нормативно-правового регулирования закупок в лечебном учреждении МО РФ 
Среди проблем осуществления закупочной деятельности в лечебном учреждении МО РФ следует отметить отсутствие корректного и быстрого взаимодействия с контролирующими органами и органами Федерального Казначейства. Как было указано выше, обмен информации происходит на бумажном или съемном машинном носителе, что увеличивает время обмена информацией и приводит к дополнительным расходам на обеспечение процесса обмена информацией (затраты на бумагу, картриджи, доставку).

Таким образом, по результатам исследования можно сделать следующие выводы.

Проблемы в процессе закупочной деятельности в лечебном учреждении МО РФ можно разделить на две группы - общие и частные, связанные со спецификой ведомства организации. К общим проблемам относятся:

1. увеличение расходов на документооборот, осуществляемый на бумажных носителях;
2. отсутствие определений ключевых понятий закупочной деятельности, таких как «эффективность закупочной деятельности», «критерии эффективности закупочной деятельности», «конкуренция в государственных и муниципальных закупках»;

3. необходимость пересмотра требований к расчету начальной (максимальной) цены контракта.

Частные проблемы в осуществлении закупок для нужд лечебного учреждения МО РФ связаны с несовершенством законодательной базы, регулирующей закупки для обеспечения нужд подведомственных организаций МО РФ, обязанностью Заказчика проводить закупки с использованием специализированной торговой площадки АСТ ГОЗ, а так же дополнительными требованиями к участникам в части материально-технического оснащения их деятельности.

\section{Библиографический список}

1. О контрактной системе в сфере закупок товаров, работ, услуг для обеспечения государственных и муниципальных нужд: федеральный закон от 05.04.2013 № 44-Ф3 // Собрание законодательства Российской Федерации от 8 апреля 2013 г. - № 14. - Ст. 1652.

2. Об особенностях осуществления закупки для нужд обороны страны и безопасности государства: постановление Правительства РФ от 27 ноября 2017 г. №1428 // Справочно-правовая система «КонсультантПлюс». - Режим доступа: http//www.consultant.ru (дата обращения: 15.08.2021).

3. Об утверждении Методических рекомендаций по применению методов определения начальной (максимальной) цены контракта, цены контракта, заключаемого с единственным поставщиком (подрядчиком, исполнителем): Приказ Минэкономразвития России от 02.10.2013 N 567 // Справочно-правовая система «КонсультантПлюс». - Режим доступа: http//www.consultant.ru (дата обращения: 15.08.2021).

4. Кнутов А.В. Управление государственными и муниципальными закупками и контрактами: учебник и практикум для бакалавриата и магистратуры. М.: Юрайт, 2019. 316 с.

5. Dadazhanova E., Tatarintsev S. Problematic issues of public procurement in medical institutions of the Ministry of Defense of the Russian Federation // Современные тенденции мирового сотрудничества: материалы IX международной молодежной научно-практической конференции на иностранных языках / Сибирский институт управления. Новосибирск, 2020. Ст. 61. 